\title{
Enhanced mobility of polydisperse granular flows in a small flume
}

\author{
Qingqing Yang ${ }^{1}$, Zhiman $\mathrm{Su}^{2}$, Fei $\mathrm{Cai}^{3}$ and Keizo Ugai ${ }^{3}$
}

\begin{abstract}
Background: A series of laboratory tests was conducted to investigate the influence of the interaction between coarse and fine particles on the mobility of granular flows in a small flume.

Methods: The angle of the upper slope was fixed at $45^{\circ}$, and the lower slope was inclined at angles of $0^{\circ}, 5^{\circ}, 10^{\circ}$, and $15^{\circ}$ in different cases. Three monodisperse materials (gravel, coarse sand, and fine sand) were mixed, and the proportion of each material in each test was varied but maintained the same total mass of $3.0 \mathrm{~kg}$.

Results: Test results show that the proportion of fine sand strongly influenced the run-out of polydisperse materials. With increasing proportion of fine sand, the run-outs of granular flows increased until its peak. However, the run-outs decreased with further more fine sand.

Discussion: The reason might be that a thin layer of fine sand acted as rollers for the rolling of the gravel, leading to the reduction of effective friction resistance during the movement; when excessive amount of fine sand was involved, these rollers were thrown into disarray so that the particles were either blocked or forced into sliding.
\end{abstract}

Conclusion: This implies that an appropriate proportion of fine particles were partly responsible for the long run-out of rock avalanches.

Keywords: Polydisperse granular flow; Run-out; Deposit morphology; Flume test

\section{Background}

Granular flows are widespread in nature as rockslides, volcanic block-and-ash pyroclastic flows, and dry rock and debris avalanches. An important feature of these flows is their extremely high mobility (up to tens of kilometers), which is capable of moving freely from their sources. Many researchers (e.g. Davies et al. 2012; Heim, 1932; Hsü, 1975; Scheidegger, 1973) reported that the mobility of these flows is dependent on their volume, indicating that large events travel farther than smaller ones. However, the long run-out granular flows moved far beyond the distance that could have been expected when considering the size effect alone (Erismann and Abele, 2001). The fundamental understanding of the propagation mechanisms of granular flows is important, in particular when geomorphological circumstances and mechanical properties of involved materials are varied according to different specific events.

\footnotetext{
* Correspondence: szmiyqq@163.com

${ }^{2}$ Chinese Academy of Sciences, Institute of Mountain Hazards and Environment, Chengdu 610041, China

Full list of author information is available at the end of the article
}

The physical behavior of dense granular flows has attracted considerable attention from laboratory experiment and numerical modeling points of view. The dynamics of the collapses of axisymmetric and two-dimensional granular columns onto a horizontal surface and the subsequent granular propagation have been investigated experimentally (e.g. Balmforth and Kerswell, 2005; Lajeunesse et al., 2005; Lube et al., 2005). The test results challenged the traditional view that the run-out depends only on the volume of the materials involved, and emphasized the importance of the initial aspect ratio of the column instead. Other researchers presented some numerical simulations to reproduce natural mass flows over complex terrains (e.g. Denlinger and Iverson, 2004; Iverson and Denlinger, 2001; Pudasaini and Hutter, 2003) and experimental flows (e.g. Pudasaini et al., 2008; Yang et al., 2014). Parameters used in the numerical simulations are usually obtained by back analyses of occurred events or by calibration, as a result of the extreme complexity of such phenomena and the still incomplete knowledge of the governing laws controlling the behavior of these materials (Crosta et al., 2009). 
Experiment plays a significant role in contributing a better understanding of propagation mechanisms and factors influencing velocity and deposit characteristics (Yang et al., 2011). A majority of previous experiments have focused on the case of monodisperse materials down inclined roughened slope (e.g. Davies et al. 1999; Manzella and Labiouse, 2013; Pouliquen, 1999). However, particles rarely have a regular shape or a uniform size distribution (Gray and Ancey, 2011). Research accounting for interactions among constitute particles with different grain sizes and shapes on the mobility of granular flows is still out of reach. Some researchers have reported that experimental granular flows containing a range of particle sizes can exhibit macro-scale properties that differ from flows containing a single particle size (Goujon et al., 2007; Moro et al., 2010; Phillips et al., 2006; Roche et al.,2006). The variety of mechanical properties can lead to a diversity and complication of behavior due to the interaction of polydisperse components. Actually, natural flows generally contain particles of a fairly wide range of sizes; in some cases, the size range of particles can vary from tens of micrometers up to the order of a meter (Roche et al., 2006). Fragmentation is a prominent process in the emplacement of field rock avalanches, and can cause materials extensively fractured/shattered (e.g. Blasio and Crosta, 2014; Crosta et al., 2007; Davies and McSaveney, 2009). Therefore considering a wide range of particle gradation is important for proper understanding of natural granular flow.

Roche et al. (2006) performed experiments on a column of fluidized particles that were released into an enclosed channel, and the behavior of fine particles is distinct from that of larger ones. They concluded that the mobility is modified when the mixture of different-sized particles was used, especially with $30 \%$ fine particles in mass proportion. Phillips et al. (2006) presented laboratory measurements of flows of binary mixtures of fine and coarse granular materials, and showed that the interaction between them can result in significantly increased mobility. They used heuristic models to illustrate that some mechanisms are likely to occur in granular flows containing a wide range of grain sizes. Degaetano et al. (2013) investigated experimentally the run-out resulting from the collapse of a granular column containing two particle species that differ in size only. They found a clear dependence of run-out on both initial mixture arrangement and proportion.

In this work, the run-out and deposition height of polydisperse materials moving over a rough inclined flume were investigated by conducting a series of laboratory experiments, and the effect of the interactions between polydisperse components on the mobility of the granular flows was examined. These granular flows contained a range of particle sizes from $0.1 \mathrm{~mm}$ to $10 \mathrm{~mm}$, which was a rather narrow range compared to those materials involved in geophysical granular flows. Determining the chief interactions with a wide size distribution is difficult, and the choice of the particle sizes in this study aided the understanding of complex particle interactions between coarse and fine particles in real events.

\section{Experiments and methods}

Experimental set-up

The two-part flume used in the tests consisted of two slopes with the upper and lower slope (Figure 1). Each

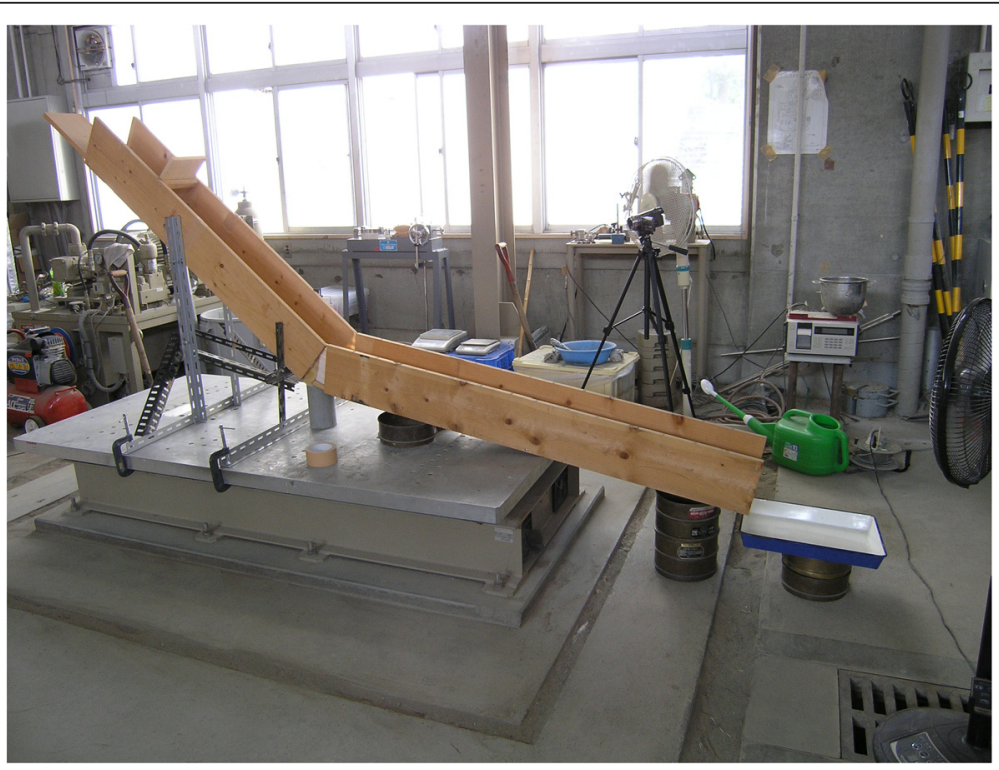

Figure 1 Experimental set-up. 


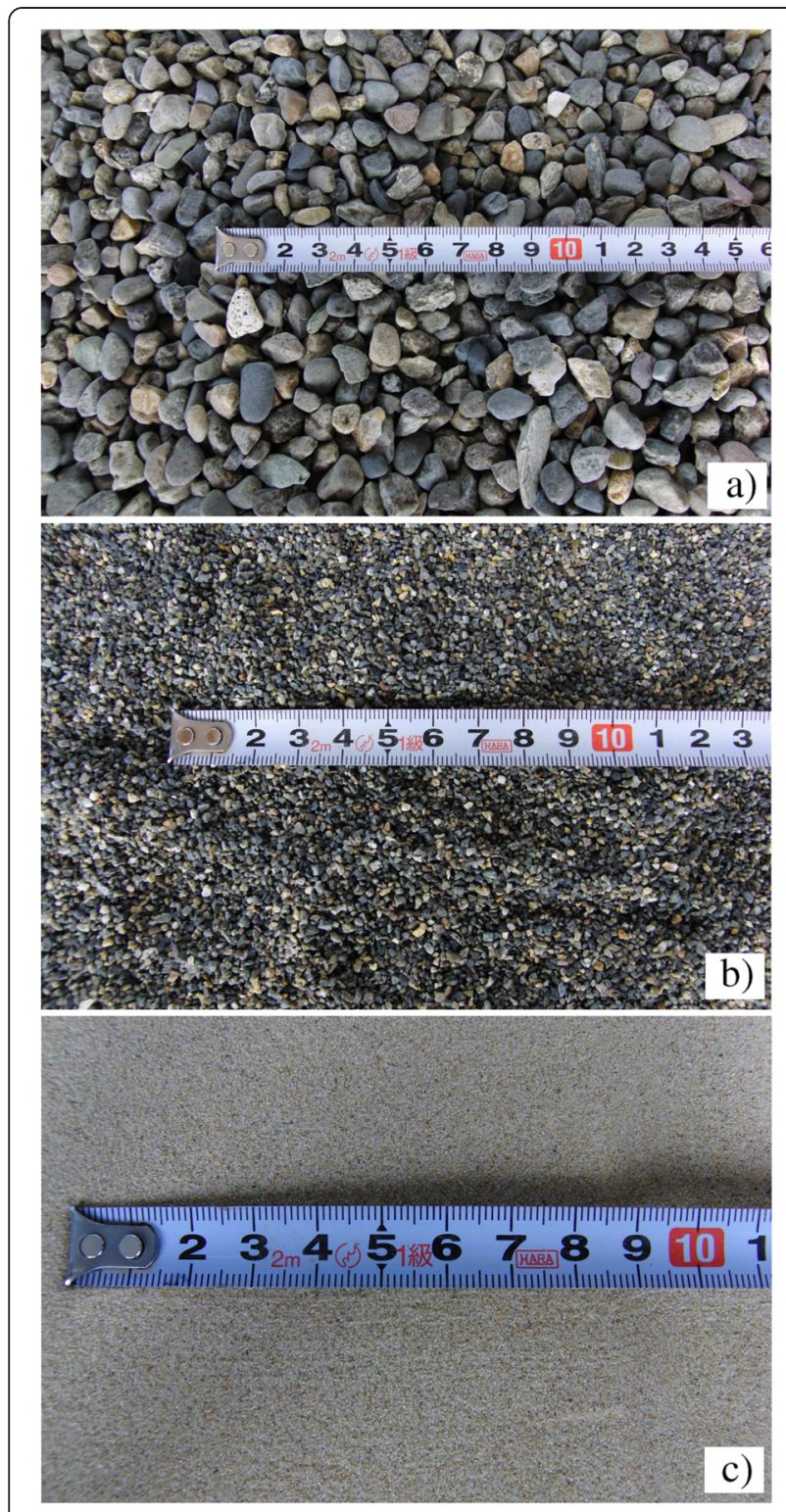

Figure 2 Granular materials used: a) Gravel; b) Coarse sand; c) Fine sand. slope was $1.5 \mathrm{~m}$ in length. The two slopes were connected by hinges that permit inclination adjustments. The angle of the upper slope was fixed at $45^{\circ}$, and the lower slope was inclined at angles of $0^{\circ}, 5^{\circ}, 10^{\circ}$, and $15^{\circ}$. The width of the flume was $0.18 \mathrm{~m}$, which was sufficiently small for the flows to be one-dimensional; it was also sufficiently large for negligible side wall effects. A gate, perpendicular to the upper slope, can be lifted manually (but rapidly).

\section{Employed materials}

Polydisperse materials were composed of three monodisperse materials in varying proportions but always maintained the same total mass of $3.0 \mathrm{~kg}$. The bulk density of the three monodisperse materials was about $2.6 \mathrm{~g} / \mathrm{cm}^{3}$, and thus the total volume of the polydisperse materials used in each test remained nearly the same. The three monodisperse materials (Figure 2) were:

a) Gravel: coarse particles; the grain size is $4.75 \sim 9.5 \mathrm{~mm}$;

b) Coarse sand: fine particles; grain size is $0.42 \sim 2.0 \mathrm{~mm}$;

c) Fine sand: Toyoura sand, which is a very fine material. The grain size is $0.1 \sim 0.3 \mathrm{~mm}$.

\section{Data acquisition}

Each test was filmed by a video camera. The run-out and deposition height were measured manually after each test. The deposit was divided into two parts based on the accumulation of particles (Figure 3). The first part, i.e. the main part of the deposit, represented the coherent main mass of the deposit. The second part, which was only a single layer, was discontinuous from the first part and easy to distinguish. The measurements (run-out, deposition height, weight) were conducted by taking into account only the main part of the deposit. Individual particles moved beyond the flume (the rest) were not considered in this study. In the literature, the run-out is commonly defined as the total horizontal travel distance from the top of the breakaway scar to the distal end of the deposit, or the horizontal distance travelled by the center of moving mass. In this work,

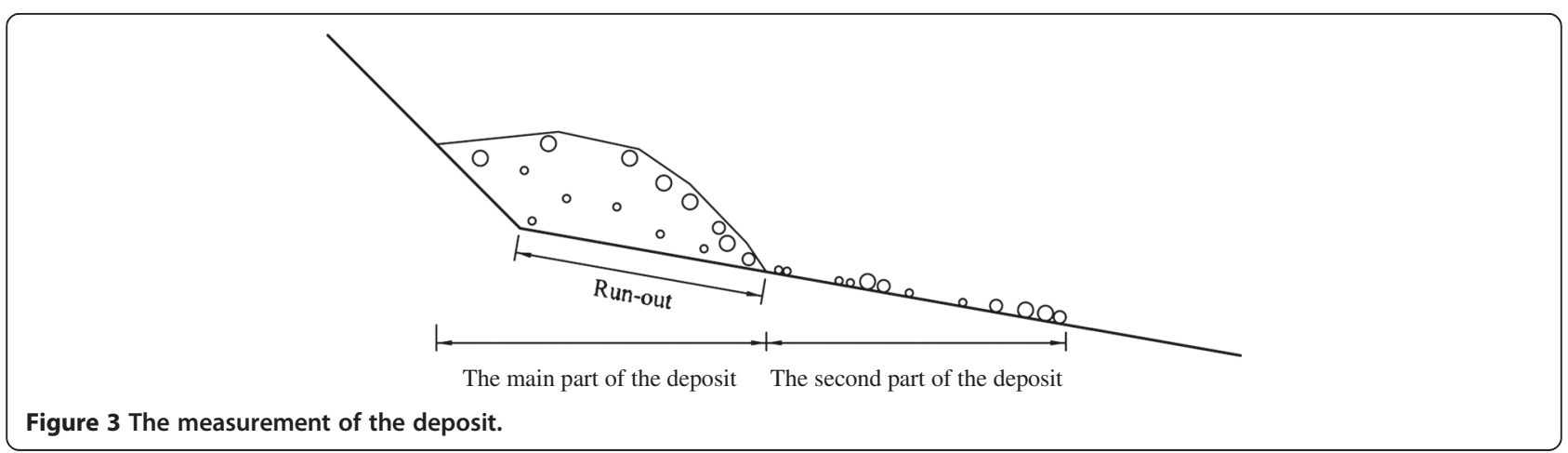


the run-out was the length of the main part of the deposit accumulated on the lower slope. This choice facilitated homogeneous results that were easy to compare. The deposition height of the main part, perpendicular to the lower slope, was measured at $10 \mathrm{~cm}$ interval along the midstream path of the lower slope.

88 cases were studied. The inclination of the lower slope $\left(0^{\circ}, 5^{\circ}, 10^{\circ}\right.$, and $\left.15^{\circ}\right)$ and the proportion of each material (gravel, coarse sand, and fine sand) were varied. Each case was repeated at least three times to evaluate the repeatability and assess the validity of the corresponding measurements. After the test, each part (i.e. the main part of the deposit, the second part of the deposit, and the rest) of the deposit was weighed respectively, and their total mass was added. The loss of particles was estimated to be less than $1 \mathrm{~g}$.

\section{Experimental results}

\section{Monodisperse material}

The run-outs of the monodisperse materials increased with the inclination of the lower slope (Figure 4). It is easy to understand that the materials had a higher mobility on steeper slopes. However, it is surprising that the run-outs of the three monodisperse materials were almost identical on the slope with the same inclination. Coarse materials would move farther than fine materials due to less energy consumption caused by intergranular friction.

The morphology of the main part of the deposit for the three monodisperse materials on the slope of $0^{\circ}, 5^{\circ}, 10^{\circ}$, and $15^{\circ}$ are shown in Figure 5, 6, 7 and 8, respectively. The deposit morphology of the three monodisperse materials was similar on the slope with the same inclination.

The mass of each material (i.e. gravel, coarse sand, and fine sand) into the second part of the deposit was weighed. The

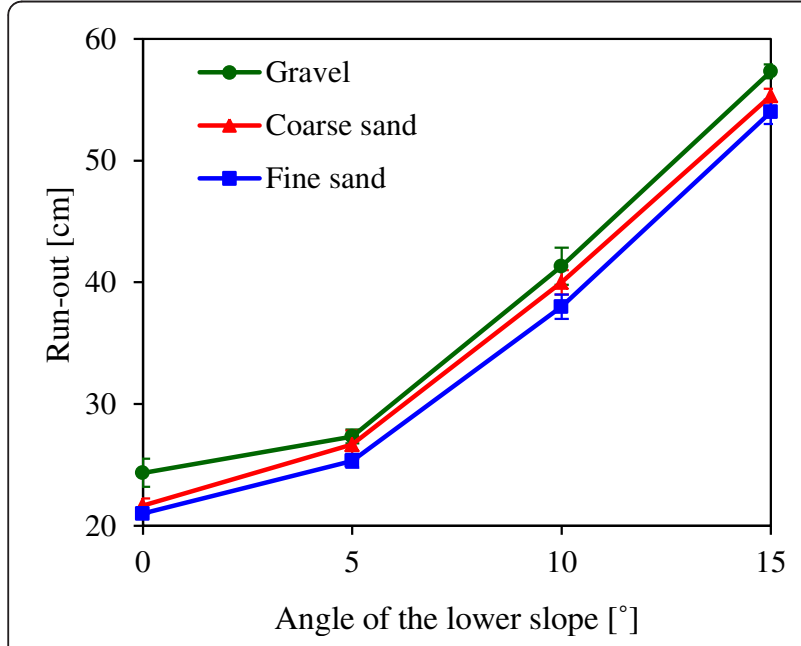

Figure 4 Run-out of the main part of the deposit for the three monodisperse materials on the slopes with different inclinations. The error bars show standard error of the average run-out for each test.

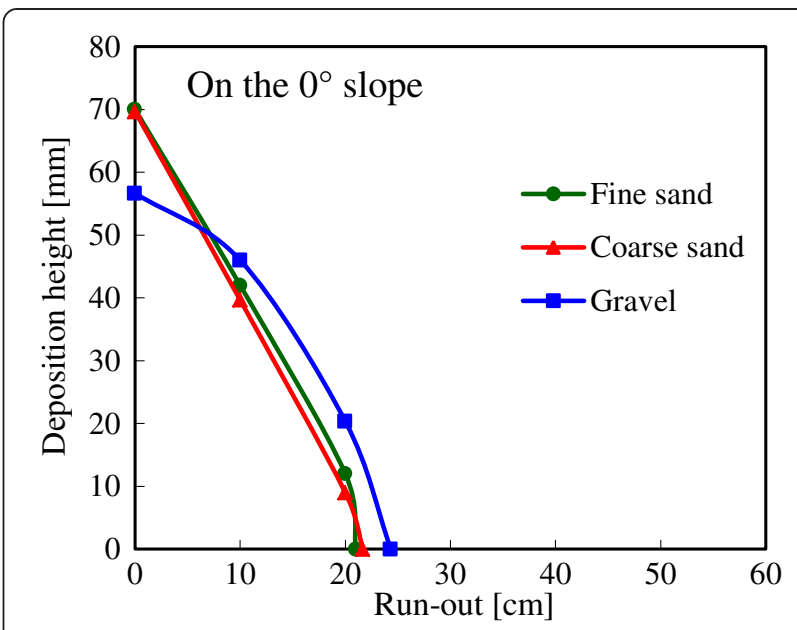

Figure 5 Deposit morphologies of the main part of the deposit for the three monodisperse materials on the $0^{\circ}$ slope.

coarser the particles, the more particles accumulated on the second part of the deposit (Figure 9). This means that coarse particles were easier to travel a long distance. The mass of the fine sand accumulated on the second part of the deposit was $1.0 \mathrm{~g}$ regardless of the inclination of the lower slope. With the increasing angle of the lower slope, more coarse sand and gravel moved far and deposited on the second part, especially for the gravel. This implies that coarse particles were prone to travel farther than fine particles on the steep slope.

\section{A polydisperse material with the same mass of gravel, coarse sand, and fine sand}

A polydisperse material was used, which consisted of $1.0 \mathrm{~kg}$ gravel $\left(\mathrm{M}_{\mathrm{g}}=1.0 \mathrm{~kg}\right), 1.0 \mathrm{~kg}$ coarse sand $\left(\mathrm{M}_{\mathrm{c}}=\right.$ $1.0 \mathrm{~kg})$, and $1.0 \mathrm{~kg}$ fine sand $\left(\mathrm{M}_{\mathrm{f}}=1.0 \mathrm{~kg}\right)$. The run-out of this polydisperse material is shown in Figure 10, combined

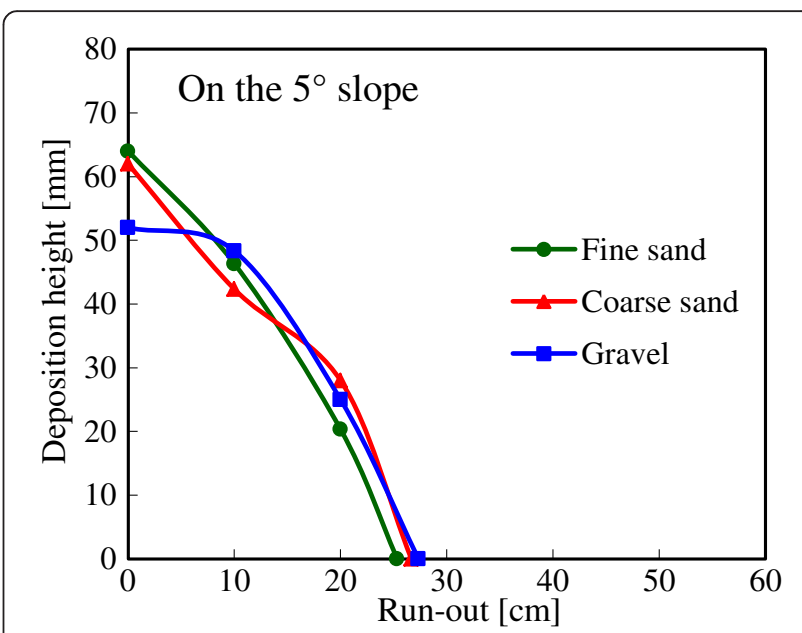

Figure 6 Deposit morphologies of the main part of the deposit for the three monodisperse materials on the $5^{\circ}$ slope. 


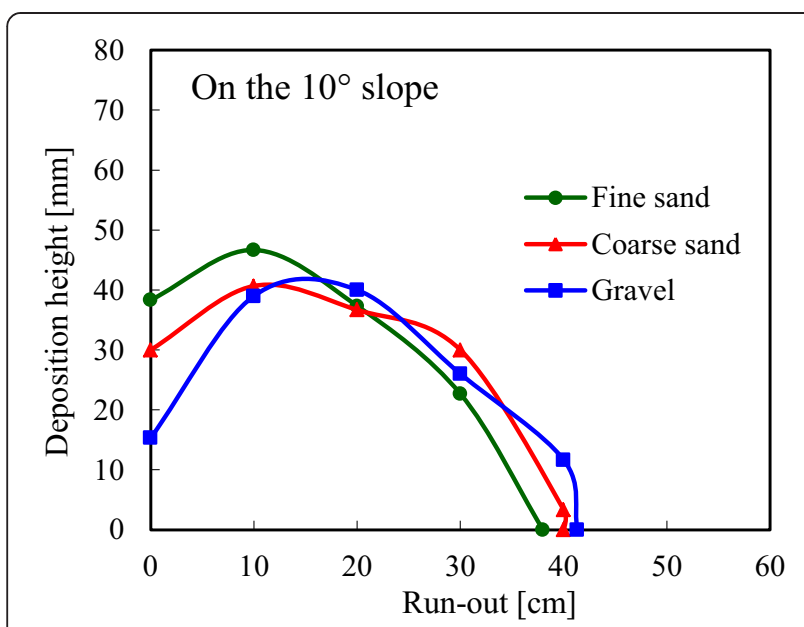

Figure 7 Deposit morphologies of the main part of the deposit for the three monodisperse materials on the $10^{\circ}$ slope.

with those of the three monodisperse materials. The mobility of the polydisperse material was significantly higher than the monodisperse materials. This implies that the interactions between coarse and fine particles were helpful to enhance the mobility of granular flows.

Figure 11 shows the deposit morphology of this polydisperse material $\left(M_{g}=M_{c}=M_{f}=1.0 \mathrm{~kg}\right)$ on the $0^{\circ}, 5^{\circ}$, $10^{\circ}$, and $15^{\circ}$ slope, respectively. Comparing with the monodisperse materials, the deposit shape of this polydisperse material was low and long.

Each case was repeated three times with this polydisperse material $\left(M_{g}=M_{c}=M_{f}=1.0 \mathrm{~kg}\right)$, and the second part of the deposit were weighted for each time (Figure 12). Less than $100 \mathrm{~g}$ of the materials accumulated on the second part of the deposit, and a majority of particles travelled a long distance.

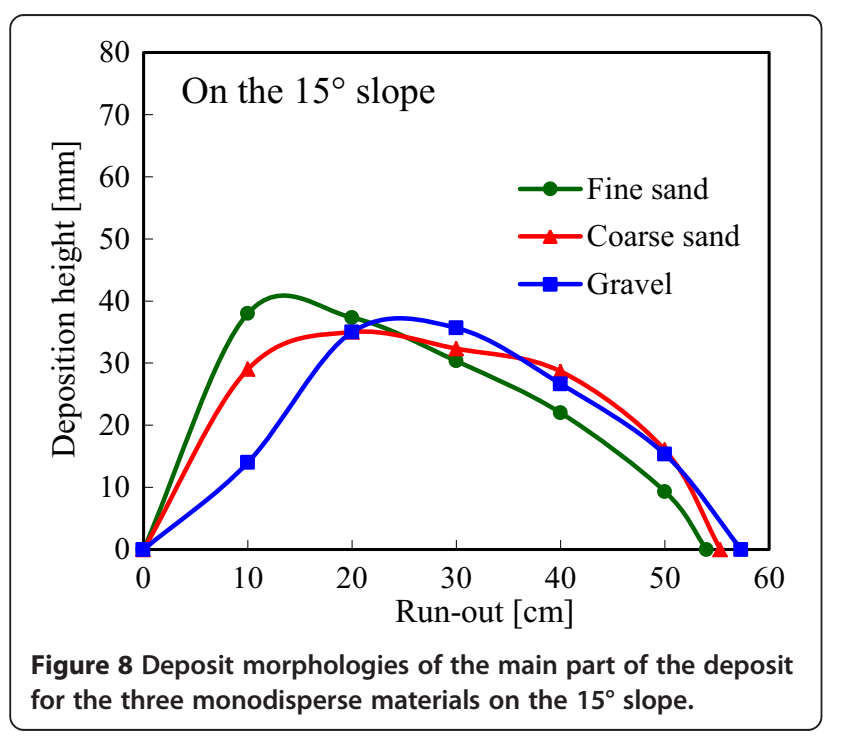

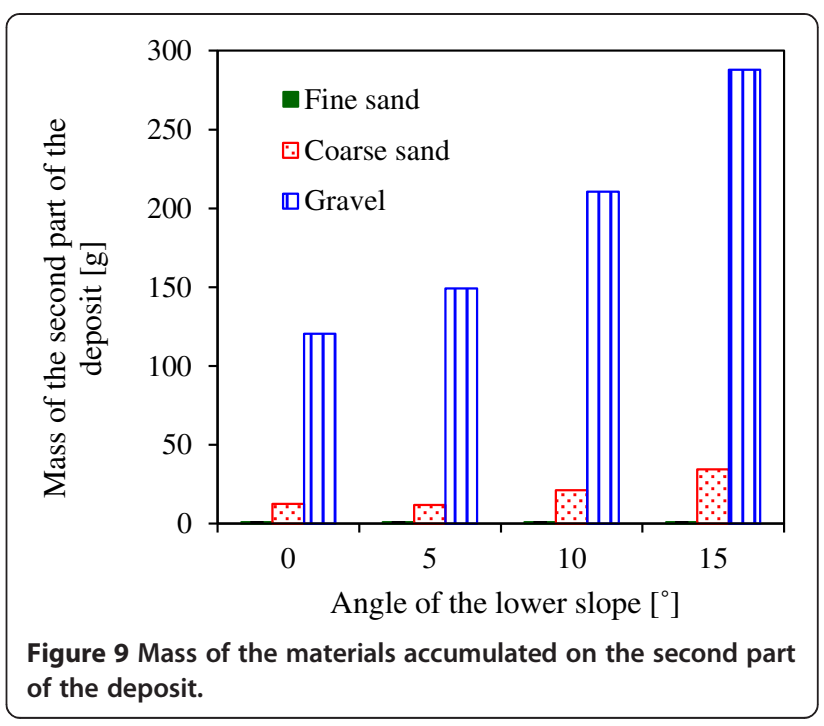

Polydisperse materials with various fractions of fine sand In order to further confirm the effect of the interactions between particles on enhancing the mobility of granular flows, polydisperse materials with various fractions of fine sand were released. In each series, the mass of the gravel was maintained $(1.0 \mathrm{~kg}, 1.4 \mathrm{~kg}$, or $1.8 \mathrm{~kg})$, and the rest consisted of coarse sand and fine sand at different mixing proportions. Fine sand mass fraction $F_{f}$ was defined as the proportion of fine sand in total mass. For example, when the mass of the gravel was $1.0 \mathrm{~kg}$, the mass of the fine sand was $0,0.4 \mathrm{~kg}, 0.8 \mathrm{~kg}, 1.2 \mathrm{~kg}$, $1.6 \mathrm{~kg}$, and $2.0 \mathrm{~kg}$, respectively. Thus, $F_{f}$ ranged from 0 (no fine sand) to 0.67 (all fine sand) when the mass of the gravel was $1.0 \mathrm{~kg}$.

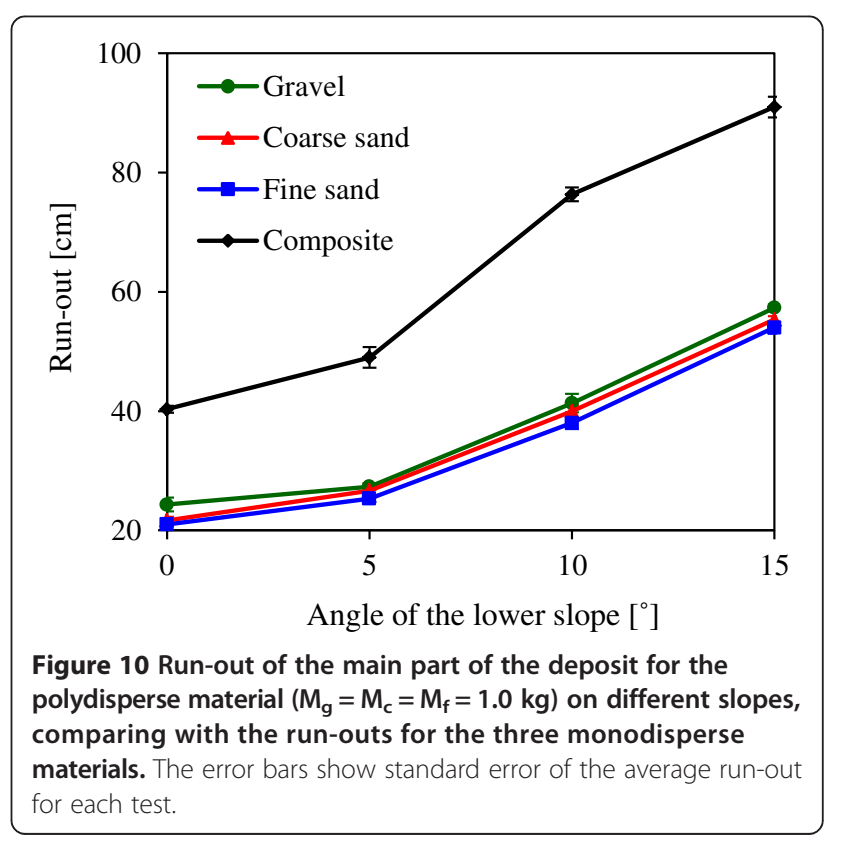




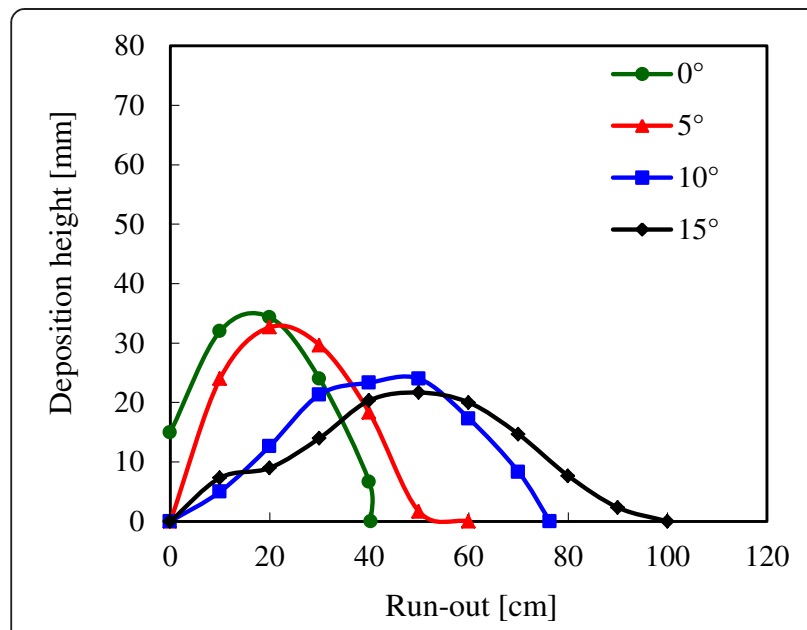

Figure 11 Deposit morphology of the main part of the deposit for the polydisperse material $\left(M_{g}=M_{c}=M_{f}=1.0 \mathrm{~kg}\right)$ on the different slopes.

Figure 13 shows the run-outs of flows on the $15^{\circ}$ slope, which were consisting of coarse and fine particles: gravel as coarse particle, and coarse and fine sand as fine particle. The mobility was enhanced due to the interactions between particles on the $15^{\circ}$ slope, except in the case with $1.0 \mathrm{~kg}$ gravel and $2.0 \mathrm{~kg}$ fine sand where the run-out of this polydisperse material was significantly smaller than that of the three monodisperse materials.

The trend of run-outs for the polydisperse materials in the three series was similar. The run-outs increased with $F_{f}$ until reaching a peak, and then decreased with further increasing $F_{f}$. This suggests that a certain amount of fine sand advanced the mobility of granular flows, and excessive amount of fine sand obstructed their propagation. The reason might be that a thin layer of fine sand acted as rollers for the rolling of the gravel, leading to the reduction of effective friction resistance during the movement; the interactions between particles became more complicated than they just acted as a single-row roller to lubricate the gravel when excessive amount of fine sand was involved. These rollers threw into disarray so that the particles might be either blocked or forced into sliding. Furthermore, from the point of view of energy, the energy was consumed significantly due to interegranular friction when excessive amount of fine sand was involved that the gravel was embedded in a matrix of fine sand.

When $F_{f}$ was small $\left(0<F_{f} \leq 0.2\right)$, the flows with $1.8 \mathrm{~kg}$ gravel (blue line, Figure 13) exhibited the highest mobility. This implies that the polydisperse material containing more coarse particles might travel farther than that with less coarse particles at small $F_{f}$. The main cause may be that the gravel typically had a high porosity, and the interactions between particles would be reduced by substituting a coarse particle for the same mass of fine particles. Frictional loss was proportional to the surface area of particles available for the interactions, and thus less energy was consumed by intergranular friction when the mass of the gravel increased.

The flow with $1.8 \mathrm{~kg}$ gravel at $F_{f}=0.13(1.8 \mathrm{~kg}$ gravel, $0.8 \mathrm{~kg}$ coarse sand, and $0.4 \mathrm{~kg}$ fine sand) travelled the longest run-out of $109 \mathrm{~cm}$; the maximum run-out of $102 \mathrm{~cm}$ was observed for the flow with $1.4 \mathrm{~kg}$ gravel at $F_{f}=0.27(1.4 \mathrm{~kg}$ gravel, $0.8 \mathrm{~kg}$ coarse sand, and $0.8 \mathrm{~kg}$ fine sand), and the peak in run-out was $98.3 \mathrm{~cm}$ for the flow with $1.0 \mathrm{~kg}$ grave at $F_{f}=0.27(1.0 \mathrm{~kg}$ gravel, $1.2 \mathrm{~kg}$ coarse sand, and $0.8 \mathrm{~kg}$ fine sand). For the polydisperse materials with different mass of gravel, the flows exhibited the highest mobility at different $F_{f}$. The interaction of particles with different sizes and shapes became more complicated when internal structure of granular flows was varied. The precise details of interactions among constituent particles are still poorly understood.

The flows containing $1.8 \mathrm{~kg}$ gravel show a peak in run-out over a range of $F_{f}$ between 0.1 and 0.2 . The peak in run-out extended over a greater range of $F_{f}$ between 0.1 and 0.3 for the flows containing $1.4 \mathrm{~kg}$ gravel, and of $F_{f}$ between 0.1 and 0.4 for the flows containing $1.0 \mathrm{~kg}$ gravel. The peak was sharper in the experiments with $1.8 \mathrm{~kg}$ gravel. This suggests that the mobility was more

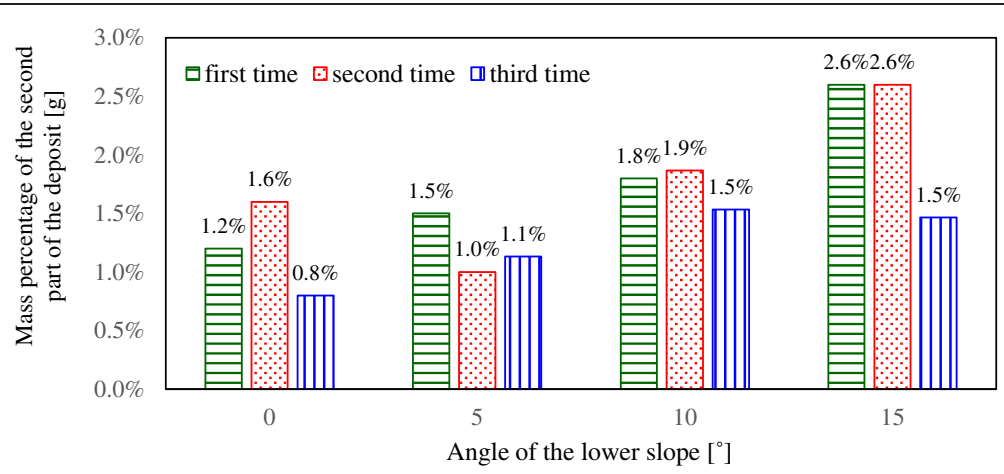

Figure 12 Mass of the second part of the deposit for the polydisperse material $\left(M_{g}=M_{c}=M_{f}=1.0 \mathrm{~kg}\right)$ over three runs on different slopes. 


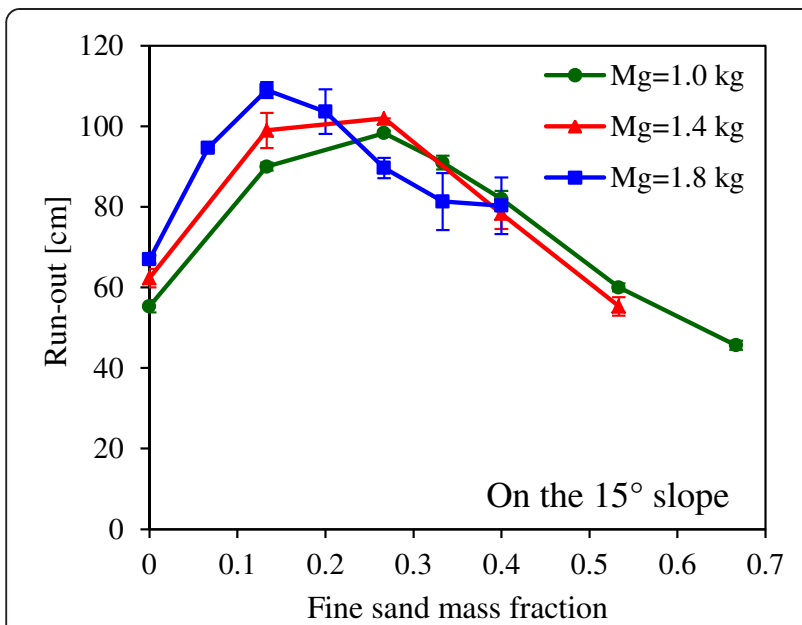

Figure 13 Run-outs of the main part of the deposit for the polydisperse materials with various fractions of fine sand on the $15^{\circ}$ slope. The error bars show standard error of the average run-out for each test.

sensitive to the proportion of fine sand when more gravel was involved.

The run-outs of flows on the slope of $10^{\circ}, 5^{\circ}$, and $0^{\circ}$ are shown in Figures 14, 15, and 16, respectively. The polydisperse materials also travelled farther than the three monodisperse materials on these slopes. The trends of run-outs were similar to that on the $15^{\circ}$ slope. However, the run-outs on the gentle slopes were shorter than that on the $15^{\circ}$ slope. This indicates that the inclination of the lower slope significantly influenced the mobility of polydisperse materials. The difference in run-out was not significant for a range of $F_{f}$ on these gentle slopes, comparing with that on the $15^{\circ}$ slope. This implies that the effect of the interactions between

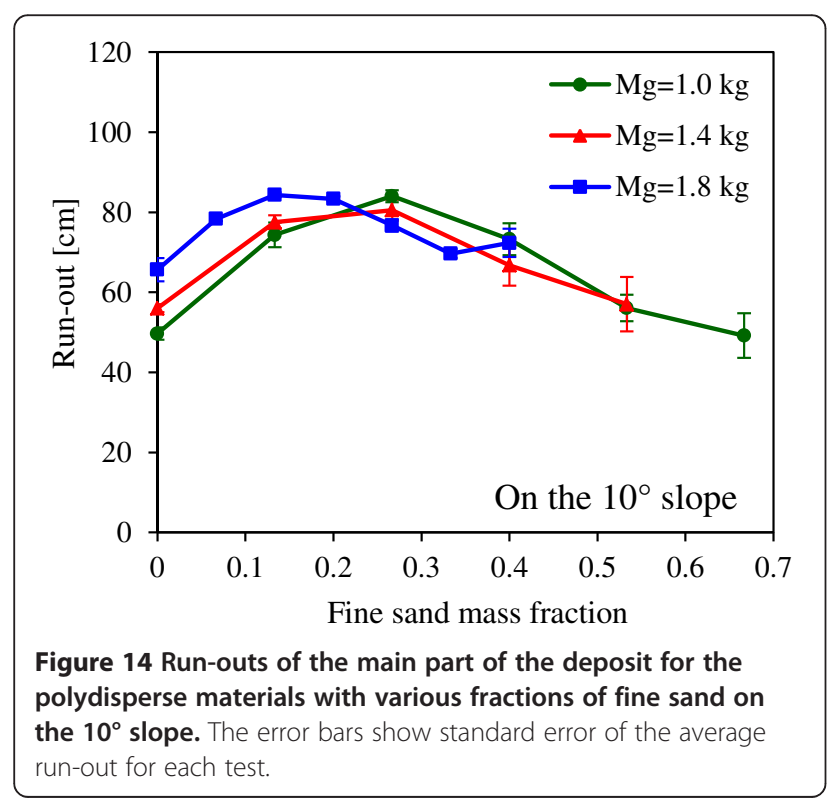

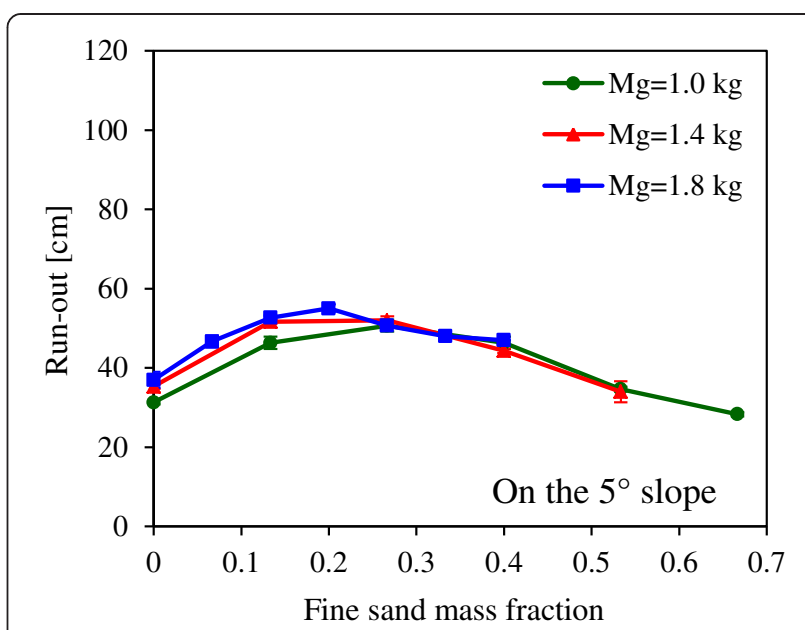

Figure 15 Run-outs of the main part of the deposit for the polydisperse materials with various fractions of fine sand on the $5^{\circ}$ slope. The error bars show standard error of the average run-out for each test.

coarse and fine particles on enhancing the mobility of polydisperse materials was not fully developed on the gentle slopes, i.e. the rolling motion did not readily occur on the gentle slopes. On the $5^{\circ}$ and $0^{\circ}$ slope, the run-outs were almost identical at large $F_{f}(0.3 \sim 0.67)$ regardless of the mass of gravel. This was because the gravel embedded in a matrix of fine sand and was difficult to move on these gentle slopes.

Figure 17 shows the deposit morphology of the main part of the deposit accumulated on the lower slope with different inclinations. The three flows, consisted of various constitute particles, were selected for comparison. Each of the three flows $\left(\mathrm{M}_{\mathrm{g}}=1.0 \mathrm{~kg}, \mathrm{M}_{\mathrm{c}}=1.2 \mathrm{~kg}, \mathrm{M}_{\mathrm{f}}=\right.$ $0.8 \mathrm{~kg} ; \mathrm{M}_{\mathrm{g}}=1.4 \mathrm{~kg}, \mathrm{M}_{\mathrm{c}}=0.8 \mathrm{~kg}, \mathrm{M}_{\mathrm{f}}=0.8 \mathrm{~kg} ; \mathrm{M}_{\mathrm{g}}=1.8 \mathrm{~kg}$,

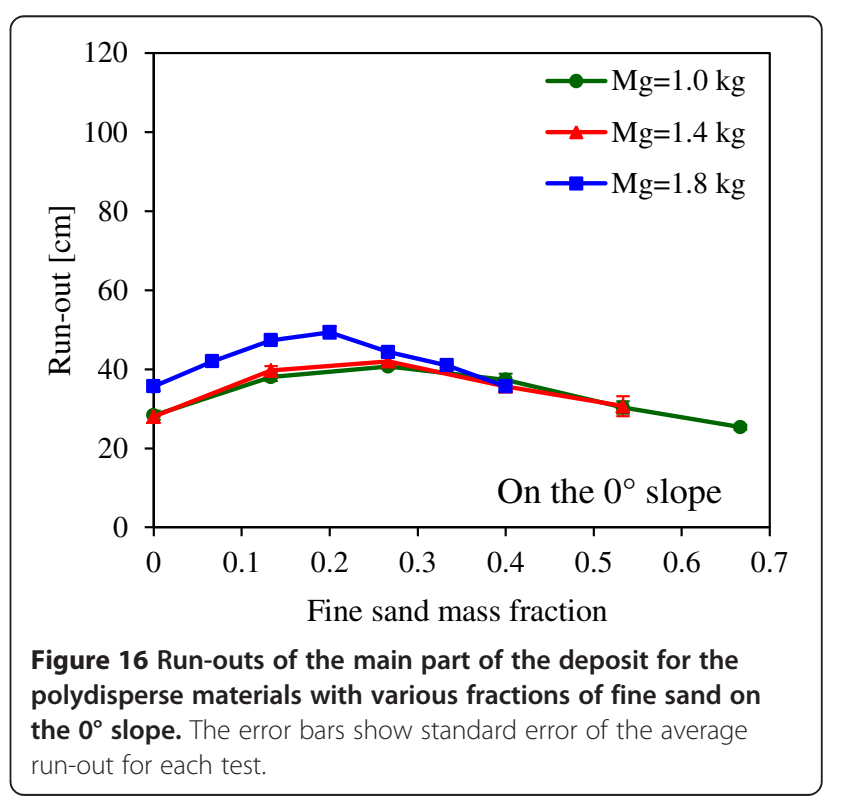



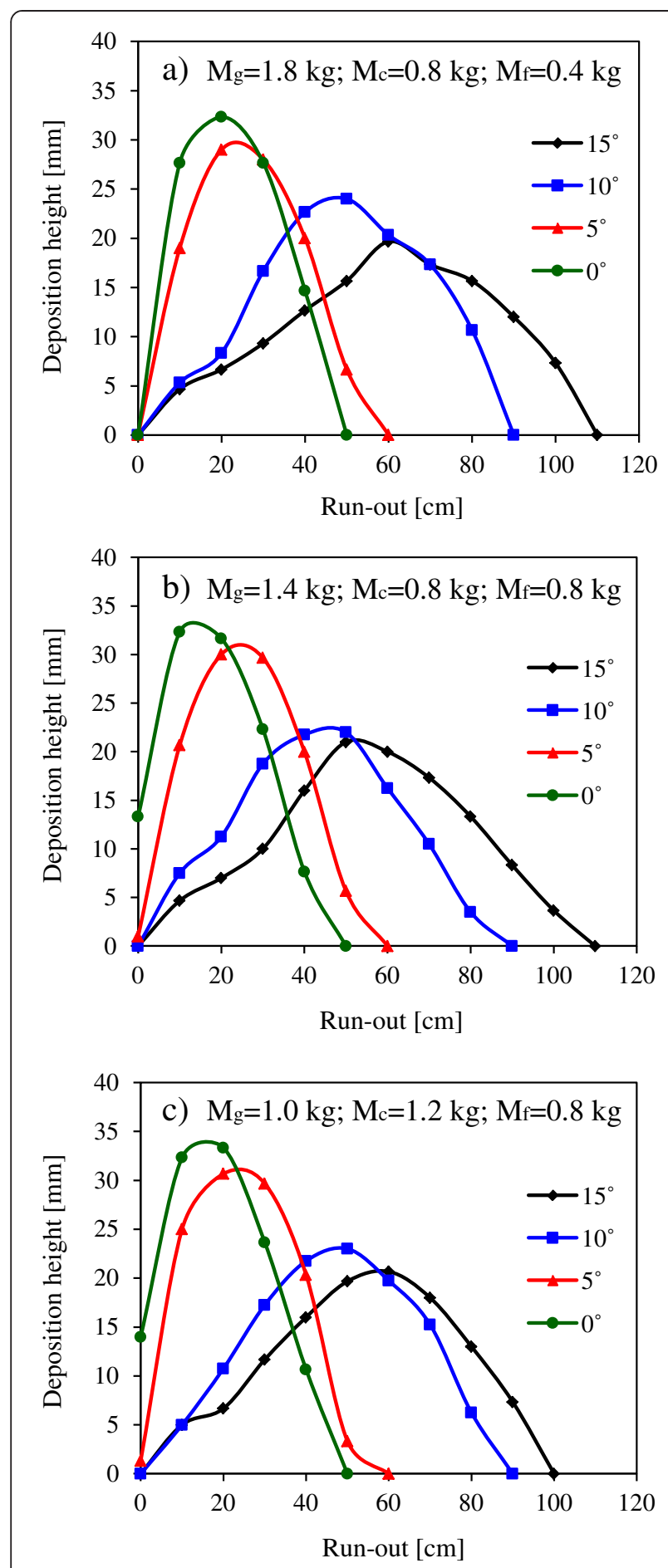

Figure 17 Deposit morphology of the main part of the deposit accumulated on the lower slope with different inclinations: a) $\left.M_{g}=1.8 \mathrm{~kg} ; M_{c}=0.8 \mathrm{~kg} ; M_{f}=0.4 \mathrm{~kg} ; b\right) M_{g}=1.4 \mathrm{~kg} ; M_{c}=$ $\left.0.8 \mathrm{~kg} ; M_{f}=0.8 \mathrm{~kg} ; \mathrm{c}\right) M_{g}=1.0 \mathrm{~kg} ; M_{c}=1.2 \mathrm{~kg} ; M_{f}=0.8 \mathrm{~kg}$.

$\mathrm{M}_{\mathrm{c}}=0.8 \mathrm{~kg}, \mathrm{M}_{\mathrm{f}}=0.4 \mathrm{~kg}$ ) typically exhibited the longest run-out in the series on the $15^{\circ}$ slope. The deposit morphologies on the steep and gentle slopes significantly departed from each other. This indicates that the deposit morphology of granular flows was also influenced strongly by the inclination of the lower slope. The deposit profile was much flatter and longer on the steep slopes $\left(15^{\circ}\right.$ and $\left.10^{\circ}\right)$ than that on the gentle slopes $\left(5^{\circ}\right.$ and $\left.0^{\circ}\right)$. This phenomenon implies that there was a critical inclination of the lower slope between $5^{\circ}$ and $10^{\circ}$ at which particle motion in flows changed in this work. When the slope was steeper than the critical inclination, the particles were prone to rolling. Otherwise, the particles exhibited sliding motion.

For all polydisperse materials used in the experiments, the deposits exhibited some common features as follows. First, coarse particles segregated to the surface of fine particles. This phenomenon is also observed frequently in field investigations. Second, the region of maximum concentration of particles was farther from the flow origin on the steeper slope, that is, more materials were transported a long distance. A broad range of granular materials accumulated from the position $20 \mathrm{~cm}$ to $90 \mathrm{~cm}$ on the $15^{\circ}$ and $10^{\circ}$ slopes. On the gentle slopes, however, the deposits concentrated a narrow range from the position $0 \mathrm{~cm}$ to the position $40 \mathrm{~cm}$. The materials were prone to contribute to add the deposition height rather than the run-out on the gentle slope. Finally, the deposit morphologies were almost similar on the same slope for the three flows with different polydisperse components. This implies that the mobility of granular flows was more sensitive to the inclination of the lower slope than granular component.

\section{Method}

The flows described in this study varied the proportion of constitute particles but maintained the same total mass to examine the effect of interactions between particles on the mobility of granular flows.

\section{Results}

Test results indicate that the run-outs of the flows with a wide range of grain sizes were larger than the flows only containing mono-sized particles. The proportion of fine sand strongly influenced the run-out of the polydisperse materials.

The fine sand was transported with the gravel, and naturally segregated to the base of the flow under gravity. The rolling of fine sand acted as a lubricant for the gravel by the interactions with each other, and thus the friction resistance reduced during the movement. With increasing $F_{f}$ a greater proportion of gravel was completely supported by the fine sand, and the run-out reached its peak. This indicates that rolling motion was very important in flow propagation, and increasing proportion of rolling to sliding in particle motion reduced energy consumption. However, the run-out decreased with further increasing $F_{f}$. This was because 
intergranular friction dominated which was the primary source of energy loss, and thus limited the propagation of granular flows.

The deposit characteristics on the steep and gentle slopes significantly departed from each other. The deposit profile was much flatter and longer on the steep slopes $\left(15^{\circ}\right.$ and $\left.10^{\circ}\right)$ than that on the gentle slopes $\left(5^{\circ}\right.$ and $\left.0^{\circ}\right)$. The region of maximum concentration of particles was farther from the flow origin on the steeper slope, i.e., more materials were transported a long distance on steep slope. This situation is riskier for human habitation and environmental protection in steep mountain slopes. On the gentle slopes, however, the deposit was more concentrated on the gentle slopes because the materials were prone to contribute to add the deposition height rather than the run-out. The deposit morphologies were almost similar on the same slope for the three flows containing different constitute particles. This implies that the mobility of granular flows was more sensitive to the inclination of the lower slope than granular components.

\section{Discussion}

The conclusion that $F_{f}$ had an influence on the run-out of granular flows is consistent with those made by other works (e.g. Degaetano et al., 2013; Phillips et al., 2006; Roche et al., 2006). This implies that an appropriate proportion of fine particles were partly responsible for the long run-out of rock avalanches. The effects of the complex particle interactions is likely to be important in controlling the dynamics of some landslides and rock avalanches, though precise details of particle interactions is still unknown because the motion of fine particles within the flows is difficult to be observed in the tests. The interactions among particles with different size need to be further studied to better understand these phenomena.

\section{Competing interests}

The authors declare that they have no competing interests.

\section{Authors' contributions}

FC and KU laid out the experiment scheme and provided discussions about the test results; QY and ZS conducted the small flume tests; QY and ZS drafted the manuscript; all authors read and approved the final manuscript.

\footnotetext{
Acknowledgement

This work is supported by National Natural Science Foundation of China (project No. 41402244), the Fundamental Research Funds for the Central Universities (project No. A0920502051413-13), and Scientific Research Foundation for Returned Scholars, Ministry of Education of China. This research is also partly supported by the Chinese State Key Basic Research Program (project 2013CB733201). Much gratefulness is extended to the two anonymous reviewers and the editors, and their comments strongly contributed in improving the quality of this manuscript.
}

\section{Author details}

${ }^{1}$ Faculty of Geosciences and Environmental Engineering, Southwest Jiaotong University, Chengdu 610031, China. ${ }^{2}$ Chinese Academy of Sciences, Institute of Mountain Hazards and Environment, Chengdu 610041, China. ${ }^{3}$ Department of Environmental Engineering Science, Gunma University, Kiryu 376-8515, Japan.

Received: 11 October 2014 Accepted: 25 February 2015

Published online: 25 April 2015

\section{References}

Balmforth NJ, Kerswell RR (2005) Granular collapse in two dimensions. J Fluid Mech 538:399-428

Blasio FVD, Crosta G (2014). Simple physical model for the fragmentation of rock avalanches. Acta Mechanica, 225(1). doi:10.1007/s00707-013-0942-y.

Crosta GB, Frattini P, Fusi N (2007) Fragmentation in the Val Pola rock avalanche, Italian Alps. J Geophys Res 112:F01006

Crosta GB, Imposimato S, Roddeman D (2009) Numerical modeling of 2-D granular step collapse on erodible and nonerodible surface. J Geophys Res 114:F03020

Davies TR, McSaveney MJ (2009) The role of rock fragmentation in the motion of large landslides. Eng Geol 109:67-79

Davies TR, McSaveney MJ, Hodgson KA (1999) A fragmentation-spreading model for long-runout rock avalanches. Can J Geotech 36:1096-1110

Davies TR, McSaveney MJ, Scarascia-Mugnozza (2012) Rock-avalanche size and run-out: Implications for landslide dams. In: Evans SG, Hermanns RL, Strom A (eds) Natural and Artificial Rockslide Dams. Springer, Heidelberg, pp 441-462

Degaetano M, Lacaze L, Phillips JC (2013). The influence of localised size reorganisation on short-duration bidispersed granular flows. Eur. Phys. J. E 36 (4), doi: 10.1140/epje/i2013-13036-9.

Denlinger RP, Iverson RM (2004) Granular avalanches across irregular three-dimensional terrain, 1. Theory and computation. J Geophys Res 109:F01014

Erismann TH, Abele G (2001) Dynamics of rockslides and rockfalls. Springer, Berlin, $\mathrm{p} 12$

Goujon C, Dalloz-Dubrujeaud B, Thomas N (2007) Bidisperse granular avalanches on inclined planes: A rich variety of behaviors. Eur Phys J E 23:199-215

Gray JMNT, Ancey C (2011) Multi-component particle-size segregation in shallow granular avalanches. J Fluid Mech 678:535-588

Heim A (1932). Bergsturz und Meschenleben. Frets und Wasmuth, 218.

Hsü KJ (1975) Catastrophic debris streams (Sturzstroms) generated by rockfalls. Geol Soc Am Bull 86:129-140

Iverson RM, Denlinger RP (2001) Flow of variably fluidized granular masses across three-dimensional terrain: 1. Coulomb mixture theory. J Geophys Res 16:537-552

Lajeunesse E, Monnier JB, Homsy GM (2005) Granular slumping on a horizontal surface. Phys Fluids 17:203302

Lube G, Huppert HE, Sparks RSJ, Freundt A (2005) Collapses of two-dimensional granular columns. Phys Rev E 72:041301

Manzella I, Labiouse V (2013) Empirical and analytical analyses of laboratory granular flows to investigate rock avalanche propagation. Landslides 10(1):23-36

Moro F, Faug T, Bello H, Ousset F (2010) Large mobility of dry snow avalanches: Insight from small-scale laboratory tests on granular avalanches of bidisperse materials. Cold Reg Sci Technol 62:55-66

Phillips JC, Hogg AJ, Kerswell RR, Thomas NH (2006) Enhanced mobility of granular mixtures of fine and coarse particles. Earth Planet Sci Lett 246:466-480

Pouliquen O (1999) Scaling laws in granular flows down rough inclined planes. Phys Fluids 11(3):542

Pudasaini SP, Hutter K (2003) Rapid shear flows of dry granular masses down curved and twisted channels. J Fluid Mech 495:193-208

Pudasaini SP, Wang YQ, Sheng LT, Hsiau SS, Hutter K, Katzenbach R (2008) Avalanching granular flows down curved and twisted channels: Theoretical and experimental results. Phys Fluids 20:073302

Roche O, Gilbertson MA, Phillips JC, Sparks RSJ (2006) The influence of particle size on the flow of initially fluidized powders. Power Technology 166:167-174

Scheidegger AE (1973) On the prediction of the reach and velocity of catastrophic landslides. Rock Mech 5:231-236

Yang QQ, Cai F, Ugai K, Yamada M, Su ZM, Ahmed A, Huang RQ, Xu Q (2011) Some factors affecting mass-front velocity of rapid dry granular flows in a large flume. Eng Geol 122:249-260

Yang QQ, Cai F, Su ZM, Ugai K, Xu LY, Huang RQ, Xu Q (2014) Numerical Simulation of Granular Flows in a Large Flume Using Discontinuous Deformation Analysis. Rock Mech Rock Engng 47(6):2299-2306 